\title{
VIDA E MORTE, PROGRESSO E UTOPIA EM HERBERT MARCUSE
}

\author{
Marília Mello Pisani ${ }^{1}$
}

\begin{abstract}
Resumo:
Neste artigo pretendo apresentar a crítica da sociedade industrial de Herbert Marcuse, em dois movimentos. Tomando como caso particular a indústria automobilística como generalização de uma forma de vida (e de morte), assim como o debate realizado sobre esse tema na década de 1970, discutirei o lugar da Utopia no pensamento de Herbert Marcuse como base para pensar os movimentos sociais contemporâneos e a própria Teoria Crítica. Para isso, mobilizo trabalhos de pesquisadores e pesquisadoras brasileiras(os), alguns textos inéditos de Marcuse e uma série de trabalhos que permitem articular uma teoria crítica do movimento social na chave da Grande Recusa e da revolução.
\end{abstract}

Palavras-chave: teoria crítica; grande recusa; antiracismo; feminismo; ecologia; Herbert Marcuse (1898-1979).

\section{LIFE AND DEATH, PROGRESS AND UTOPIA IN HERBERT MARCUSE'S}

\begin{abstract}
:
In this article I intend to present the criticism of the industrial society of Herbert Marcuse in two movements. Taking the automobile industry as a particular case for the generalization of a way of life (and death), as well as the debate on this theme in the 1970s, I will discuss the place of Utopia in Herbert Marcuse's thinking as a basis for thinking the social movements and Critical Theory itself. To this end, I mobilize the works of Brazilian researchers, some unpublished texts of Marcuse in Brazil, and a series of papers that allow articulating a critical theory of the social movement in the key of the Great Refusal and revolution.
\end{abstract}

Keywords: critical theory; great refusal; antiracism; feminism; ecology; Herbert Marcuse (1898-1979).

\section{Nota introdutória}

Este artigo pretende discutir a crítica da sociedade industrial de Herbert Marcuse à luz de suas concepções de Utopia e de Grande Recusa, articuladas ao seu modo de pensar os movimentos sociais contemporâneos do período de 1967-1979. A motivação desta escrita, entretanto, não vem de uma vontade em esclarecer o pensamento de Marcuse sobre estes problemas. O problema deste ensaio não emerge da tentativa de elucidação do pensamento de Marcuse. Na verdade, a força que mobiliza a mão e o corpo que escreve é derivada de uma necessidade vital e biológica de elaboração de um luto.

Maria Érbia Carnaúba faleceu no dia 26 de agosto de 2017 em um acidente de carro no

\footnotetext{
${ }^{1}$ Possui doutorado em Filosofia (UFSCar, 2008), mestrado em Filosofia (UFSCar, 2003), bacharelado e licenciatura em Ciências Sociais (UNESP, 1999). Atualmente é professora adjunta da Universidade Federal do ABC nos cursos de graduação em Filosofia e nos Bacharelados Interdisciplinares. Na pós-graduação, atua nos cursos de mestrado acadêmico em Filosofia e mestrado profissional em Filosofia (PROF-FILO). E-mail: marilia.m.pisani@gmail.com.
} 


\section{VIDA E MORTE, PROGRESSO E UTOPIA EM HERBERT MARCUSE}

Marília Mello Pisani

aeroporto do Viracopos, Campinas, quando levava a amiga Carolina Blasio (que havia defendido o doutorado em Filosofia no dia anterior) para pegar um avião. Em uma curva mal sucedida, o carro despencou com as duas de uma ponte, caindo de ponta cabeça e levando, em segundos, as duas vidas, em questão de segundos... Recebi a notícia na manhã do dia 27. Eu não conseguia acreditar. Não havia sentido nenhum no desaparecimento absoluto de Maria. Eu nunca mais a veria. Ela não estaria na banca, como titular externo, de meu primeiro orientando de mestrado a defender uma dissertação sobre Marcuse, como já estava agendado acontecer. Eu não teria nunca a oportunidade de discutir com ela a sua tese de doutorado defendida em março do mesmo ano. Maria seria, sem dúvida, uma das maiores pesquisadoras de Marcuse no Brasil. Maria e eu não tivemos a oportunidade da convivência, mas tínhamos vínculos profundos de respeito pelo trabalho que realizávamos e foi compartilhando o mesmo autor, e as mesmas angústias e esperanças, que Herbert Marcuse nos ligou. E é ele que chamo para nos ligar neste texto. Sinto como se as palavras que escrevo aqui permitissem fixar para além da passagem do tempo uma materialidade profunda de admiração e as saudades dela. As lágrimas são impossíveis de conter. Mas quero e preciso fazer isso. Porque eu não aceito a morte de Maria, ela não é um fato natural da vida. Eu recuso esta morte e desta recusa vem a força para este esforço de pensar, junto com Herbert Marcuse e com Maria Érbia, que isso não deveria ter acontecido. A sua morte é, nesse sentido, um signo. Sobre isso, farei uma longa citação de Marcuse, citação esta que ela com certeza conhecia muito bem e que me surpreende agora que ela seja o disparador fundamental deste texto, que é uma homenagem, uma despedida e uma celebração pela vida de Maria. No final de seu livro Eros e civilização: uma interpretação filosófica do pensamento de Freud (1999a), Marcuse escreve:

Não os que morrem, mas os que morrem antes de querer e dever morrer, os que morrem de agonia e de dor, são a grande acusação lavrada contra a civilização. Também servem de testemunho para a culpa irredimível da humanidade. A morte deles suscita a dolorosa consciência de que foi desnecessária, de que poderia ter sido de outra maneira. São precisos todos os valores e instituições de uma ordem repressiva para pacificar a má consciência dessa culpa. (...) Numa civilização repressiva, a própria morte torna-se instrumento de repressão. Quer a morte seja temida como uma constante ameaça ou glorificada como supremo sacrifício, a educação para o consentimento da morte introduz um elemento de abdicação da vida, desde o princípio - abdicação e submissão. Sufoca os esforços utópicos. (...) A Teologia e a Filosofia concorrem entre si na celebração da morte como uma categoria existencial: pervertendo um fato biológico para torná-lo uma essência ontológica, concedem suas bênçãos transcendentais à culpa da humanidade que ambas ajudam a perpetuar; assim, atraiçoam a promessa de utopia. Em contraste, uma Filosofia que não trabalha como dama de companhia da repressão reage ao fato

da morte com a Grande Recusa - a recusa de Orfeu, o libertador. A morte pode torna-se um símbolo da liberdade. (...) Os [seres humanos] podem morrer sem angústia se souberem que o que eles amam está protegido contra a miséria e o esquecimento. (...) Mas até o advento supremo da

\begin{tabular}{|l|l|l|l|l|}
\hline Revista 2 ialectus & Ano 8 & n. 14 & Janeiro-Julho 2019 & p. 147 - 168 \\
\hline
\end{tabular}




\section{VIDA E MORTE, PROGRESSO E UTOPIA EM HERBERT MARCUSE}

Marília Mello Pisani

liberdade não pode redimir aqueles que morrem de dor. É a recordação deles [e delas] e a culpa acumulada contra as suas vítimas que obscurecem as perspectivas de uma civilização sem repressão (Marcuse: 1999a: 203-204).

Como pesquisadora de Marcuse, Maria defendeu, em 2012, a dissertação de mestrado Marcuse e a Psicanálise: teoria crítica sob a análise da teoria da repressão (2012) onde trabalhou a noção de sociedade repressiva a partir dos conceitos de mais-repressão e de princípio de desempenho. Para isso, ela retomou a singular apropriação de Freud feita por Marcuse e articulou esse debate à gênese mesma da noção de Teoria Crítica, terminando com o capítulo intitulado "O retorno à utopia" que já indicava posteriores desdobramentos de sua pesquisa de doutorado, Teoria crítica e Utopia (2017). O cerne de sua produção intelectual é o apelo em demonstrar a importância da noção de Utopia de Marcuse para a Teoria crítica. No doutorado, ela esmiúça o percurso do conceito de utopia em Marcuse: o debate com Max Horkheimer, Theodor Adorno e Ernst Bloch e a aliança fundamental entre teoria e prática, que teria permitido a Marcuse estabelecer um diálogo muito próximo aos movimentos sociais a partir de 1967, como vemos no ensaio de Marcuse O Fim da Utopia, e que seguirá até o fim de sua vida, em 1979. Neste artigo pretendo seguir muito de perto o percurso proposto por ela, mas em termos que me permitam elaborar como a crítica da sociedade industrial e a noção de Grande Recusa poderiam nos ajudar a levar a sério a intenção que movimenta este modelo de Teoria crítica proposto por Marcuse: "de que a vida humana é digna de ser vivida, ou melhor, pode ser e dever ser feita digna de ser vivida. Esse juízo subjaz a todo esforço intelectual; é o a priori da teoria social e sua rejeição (que é e perfeitamente lógica) refuta a própria teoria” (Marcuse: 2015: 32).

\section{Carro e Morte: a generalização do automóvel como forma de vida}

(...) num bom automóvel a própria carroceria obedece à necessidade interna do motor, a expressão fisionômica dessas figuras obedece ao que está dentro. Ao que está dentro, e não à interioridade: é por isso que elas são bárbaras (Benjamin: 1994: 116).

O acidente que levou Maria não teve até este momento uma explicação satisfatória. Tentaram responsabilizá-la, por estar dirigindo de chinelos. Mas as explicações isoladas não dão conta. Há uma aliança de fatores: uma curva muito acentuada num trecho de entrada de um aeroporto, a pressa para deixar a amiga, uma ponte nova construída para embelezar o espaço, mais do que para proteger as/os motoristas. Uma ponte de vidro, que não foi capaz de segurar o

\begin{tabular}{|l|l|l|l|l|}
\hline Q Povista Dialectus & Ano 8 & n. 14 & Janeiro-Julho 2019 & p. $147-168$ \\
\hline
\end{tabular}




\section{VIDA E MORTE, PROGRESSO E UTOPIA EM HERBERT MARCUSE}

Marília Mello Pisani

carro, função de proteção que deveria ser prioritária na construção da ponte, ainda mais naquele lugar. Um muro fake projetado por uma empresa guiada pelas necessidades da moda das mercadorias. Os prédios de vidro não aquecem no inverno e são quentes no verão. Nos muros de vidro a transparência oculta a percepção de sua barbárie.

Recordando Walter Benjamin. Em Experiência e Pobreza (1994) ele mostra que o vidro aparece como o material por excelência da forma mercadoria na sociedade capitalista tecnologicamente desenvolvida: "Não é por acaso que o vidro é um material tão duro e tão liso, no qual nada se fixa. E também um material frio e sóbrio. As coisas de vidro não têm nenhuma aura. O vidro é em geral inimigo do mistério" (1994: 118). E se pergunta: os edifícios de vidro não professariam uma nova pobreza da experiência? Benjamin acompanha as mudanças na forma mercadoria, a passagem do interior burguês, com sua intimidade de bibelôs, cortinas com franjas, poltronas, esses "espaços de pelúcia", para o novo modelo industrial e tecnológico com a eliminação da interioridade, dos rastros, da memória e da própria experiência. Já não há o que narrar, tudo começa sempre de novo, não há tempo para se lembrar. A memória impregnada na materialidade das coisas e nas histórias contadas de geração a geração são eliminadas juntamente "com seu vidro e com a Bauhaus de aço": "eles criam espaços em que é difícil deixar rastros" (Benjamin: 1994: 118). Parafraseando o escritor Paul Scheebart, Benjamin escreve: "podemos falar de uma cultura de vidro. O novo ambiente de vidro mudará completamente os homens." (1994: 118).

Benjamin escreveu essas palavras em 1933. Quarenta anos depois, o ecologista francês René Dumont escreveu o livro A Utopia ou a Morte (1975) no qual apresentou um diagnóstico severo daquilo que Walter Benjamin começou a entrever, a saber, a submissão total da vida humana e da natureza à necessidade de um modelo de desenvolvimento econômico centrado na exploração de matéria prima e no lucro, na produção de desigualdades e na concentração de renda, enfim, a mola propulsora do capitalismo. O diagnóstico é radical, assim como as soluções propostas por ele. Tomando o carro como o modelo por excelência deste processo, Dumont consegue estabelecer as mediações que fazem do carro o objeto privilegiado para a compreensão das formas contemporâneas de vida.

A escolha pelo carro como mercadoria foi resultado de uma decisão econômica estratégica. Em torno do automóvel se construiu a vida em amplo sentido e se produziu o mercado monopolizado da locomoção humana baseado no petróleo. Este modelo produtivo define a cartografia dos territórios e o uso dos espaços, com seus viadutos, pontes, ruas, estradas,

\begin{tabular}{|c|c|c|c|c|}
\hline Q Rovita Dialectus & Ano 8 & n. 14 & Janeiro - Julho 2019 & p. $147-168$ \\
\hline
\end{tabular}




\section{VIDA E MORTE, PROGRESSO E UTOPIA EM HERBERT MARCUSE}

Marília Mello Pisani

estacionamentos, fábricas, oficinas e postos de combustíveis, entre outros. Estas políticas econômicas de desenvolvimento foram tomadas por pequenos grupos de interesse articulados em torno do Clube de Roma (Dumont: 1975: 60-61) onde se decidiu acerca da gestão mundial dos recursos naturais e energéticos, das populações e do modelo de desenvolvimento científico e tecnológico. O impacto dessas tomadas de decisões exteriores afetam profundamente as localidades.

Se tomarmos o exemplo da região do ABC paulista (sobretudo as cidades de Santo André e de São Bernardo do Campo), polo da indústria automobilística na década de 70-80, podemos analisar esta situação de dependência em outros tipos de acordos internacionais, como o Consenso de Whashington (Alves: 2009: 16-17). Luiz Roberto Alves nos ajuda a pensar sobre isso. Em seu texto Grande ABC: culturas que excedem o lugar culturalizado (2009) ele apresenta algumas das principais consequências culturais das diferentes alianças e tensões entre o capital e o trabalho na região. Do dirigismo paternalista sob a ditadura militar, que fomentou a grande indústria, às sociedades recém democratizadas, o modelo político econômico dependente das regulações do capital internacional levaram ao "despedaçamento das relações de trabalho, a fragmentação dos espaços urbanos e rurais, o fim das utopias e a submissão de tudo à economia e ao jogo do mercado. Certamente a cultura compôs e compõe o quadro de desencanto programado pelo Capital” (2009: 17). Nesse momento acontece, segundo o autor, uma nova rodada de apropriação da cultura pelo Capital, a partir do chamado capital cultural ou humano, com consequências profundas para a região. Esse exemplo mostra o quanto a dependência de modelos econômicos exógenos pode afetar a vida nas localidades distantes das tomadas de decisões.

A exportação desse modelo de vida para outras sociedades tem consequências graves e dificilmente reversíveis sem uma transformação radical, diz Dumont: "aumentamos a miséria do Terceiro Mundo", tornamos o ar irrespirável, "gastamos preciosos litros de ouro negro, que faltarão a nossos descendentes" (1975: 61). Segundo ele, cada carro produzido representa aço a menos para os arados dos camponeses e outras ferramentas que poderiam aumentar a sua produtividade local e a distribuição dos recursos necessários à vida. A escolha pelo carro implicaria, nessa perspectiva, a recusa de outros tantos modelos de desenvolvimento, de formas de vida e de culturas.

O aço, os outros materiais, os engenheiros, os técnicos e os operários que os constroem, todos os recursos raros e toda a atividade competente, se fossem dirigidos para outras finalidade, teriam já

\begin{tabular}{|l|l|l|l|l|}
\hline Qevista Dialeatus & Ano 8 & n. 14 & Janeiro-Julho 2019 & p. 147-168 \\
\hline
\end{tabular}




\section{VIDA E MORTE, PROGRESSO E UTOPIA EM HERBERT MARCUSE}

Marília Mello Pisani

podido prover por toda a parte uma indústria suficiente para cobrir o conjunto de necessidade essenciais dos países ditos em via de desenvolvimento. (...) Quanto ao Brasil, por muito pouco não fui ali atropelado, quando julgava que um sinal vermelho me protegia. Fala-se ultimamente sobre estes acidentes de carro e centenas de milhares de feridos (...) 'sacrificam-se sem pena a habitação, ensino, telefone, urbanismo, pesquisa cientifica, cultura artística, e a própria saúde pública’, para citar [algumas de suas] vítimas (Dumont: 1975: 61-62).

Segundo André Gorz, esta crítica do carro como modelo de desenvolvimento não é facilmente aceita nem pela direita nem pela esquerda: "por que o carro é tratado como uma vaca sagrada?", por que não é reconhecido como algo "antissocial"? (Gorz: 2005: 74-75). Por conta da ideologia que ronda o carro, que produz aquilo que Gorz chama de "mito automobilístico", apenas uma recusa radical deste modelo de locomoção monopolizada pela indústria de petróleo e suas adjacentes poderia religar as populações, os territórios e suas culturas, ou melhor, fazer da vida digna de se viver, como diria Marcuse. Para Gorz:

a generalização do carro particular golpeou os transportes coletivos, alterou o urbanismo e o habitat e transferiu ao carro certas funções que a sua própria difusão tornou necessárias. Será preciso uma revolução ideológica ('cultural') para quebrar esse círculo vicioso. Obviamente não se deve esperar isso da classe dominante (de direita ou de esquerda) (Gorz: 2005: 75).

Para ele há um paradoxo interno a esse mito do carro: o fato de que a liberdade de ir e vir que ele proporciona está indissociavelmente ligada às necessidades que o uso do carro implica, como congestionamentos, estacionamentos, multas e manutenção, o que, no final das contas, não se reverte em mais tempo hoje do quando se tinha outras alternativas, como bondes, charretes, carroças e bicicletas (ele se apoia no texto Energia e Equidade, de Ivan Ilich). A organização urbana, com seus bairros e locais de trabalho distantes, faz parte das necessidades mesmas do carro. Ou seja, a geografia das cidades é definida e construída para os carros, e não para as pessoas, a partir de uma necessidade vinda do capital monopolista que "transformou o supérfluo em necessário" (Gorz: 2005: 79). A aparente necessidade vital de se possuir carros, que produz a aparência de que o carro é símbolo de progresso, precisa ser desmistificada: primeiro, a partir do estudo de sua gênese (práticas, decisões, valores) e de como ele configura o mundo tal como vemos; e segundo, a partir do confronto entre o que é e as possibilidades de um outro desenvolvimento social materialmente possível, ou seja, das possibilidade negadas de desenvolvimento: "tão logo o carro assassinou o carro [quer dizer, os seus benefícios passam a ser confrontados com os custos], ele fez com que as alternativas de mudança desaparecessem, tornando compulsório, deste modo, o carro" (Gorz: 2005: 80).

René Dumont propõe que apenas por meio do pensamento utópico podemos ver as

\begin{tabular}{|l|l|l|l|l|}
\hline Q Rovista Dialactus & Ano 8 & n. 14 & Janeiro-Julho 2019 & p. 147-168 \\
\hline
\end{tabular}




\section{VIDA E MORTE, PROGRESSO E UTOPIA EM HERBERT MARCUSE}

Marília Mello Pisani

possibilidades negadas de um caminho alternativo para o desenvolvimento - "utopias mais ou menos realizáveis", ele diz. Seriam utópicas se "olhadas principalmente pelos ricos dos países ricos, e os ricos dos países pobres", que não admitirão renunciar a seus privilégios. Faço aqui um breve apanhado de algumas destas utopias realizáveis de Dumont: mudar a atitude com os países colonizados e explorados, para diminuir o abismo que os separa - por exemplo, por meio da anulação das dívidas, fornecimento de equipamentos, outra política de alimentos e energia; limitação e posterior supressão dos armamentos; redistribuição de renda, imposto internacional para grandes transações financeiras, interrupção dos ritmos infernais; reciclagem, imposto sobre energia e matéria prima; transportes coletivos; viagens aéreas racionalizadas e reduzidas como resultado do fomento a outros meios de locomoção; alimentação para todos; reforma agrária; nova política com relação aos oceanos (Dumont: 1975: 166-167). Tudo isso sob o princípio de que a natureza não é uma fonte inesgotável de energia; de que a vida humana e a natureza devem ser favorecidas; que o direito à dignidade e à vida devem ser efetivos.

André Gorz também afirma que apenas uma mudança em escala global seria eficiente neste sentido. Isso significaria não apenas oferecer transporte coletivo, mas, seria preciso poder

(...) dispensar por completo o transporte por se sentirem em casa em seus bairros, nas suas comunidades, nas suas cidades, construídos em escala humana, e por terem prazer em andar do trabalho para a casa a pé ou, se preciso for, de bicicleta. Nenhum meio de transporte e evasão veloz jamais compensará a desgraça de se viver em uma cidade inabitável em que ninguém se sente em casa em lugar algum, ou se passar somente para ir trabalhar ou, ao contrário, para se isolar e dormir (Gorz: 2005: 81).

As ruas da cidade dos carros ficam esvaziadas de noite, pois elas não são para estar, mas para passar. É justamente pelo enraizamento profundo deste modo de vida que a solução, se possível, deveria ser pensada em termos radicais, ou revolucionários, como afirma Gorz, apoiando-se em Marcuse: "Tal como respondeu Marcuse quando the perguntaram como as pessoas gastariam seu tempo após a revolução, quando o desperdício capitalista tivesse sido terminado: 'Vamos tratar de destruir as grandes cidades e construir novas e distintas. Isso nos manterá ocupados por um bom tempo" (Marcuse apud Gorz: 2005: 81). O fim da cidade dos carros como um princípio revolucionário - é disso que se trata. O texto de Gorz também foi escrito em 1973, tal como o de Dumont. A década de 70 é crucial para pensarmos a contribuição de Marcuse sobre as consequências da sociedade industrial avançada ou capitalismo monopolista e as formas de resistência.

\begin{tabular}{|c|c|c|c|c|}
\hline Qevista Dialectus & Ano 8 & n. 14 & Janeiro - Julho 2019 & p. $147-168$ \\
\hline
\end{tabular}




\section{VIDA E MORTE, PROGRESSO E UTOPIA EM HERBERT MARCUSE}

Marília Mello Pisani

Hoje é dia 20 de junho de 2018. As dezesseis horas e trinta minutos eu decidi sair para caminhar. Havia terminado a primeira parte do argumento do artigo, que coloca o carro no centro de uma crítica da civilização industrial, quando resolvi fazer uma breve caminhada para pensar na articulação do segundo movimento. Decidi pegar a Avenida Sumaré que, apesar de ser uma via de muito tráfego, tem uma pista de ciclismo e corrida bem ao meio, dividindo as duas faixas da rua. Quando cheguei e comecei a dar os primeiros passos, senti-me constrangida. O cheiro da gasolina exalava muito forte das fileiras de carro à direita e à esquerda. Insisto e resolvo caminhar assim mesmo, já que esta pista de corrida tem árvores centenárias belíssimas. No meio do caminho, desisto, intoxicada estou pelo escapamento dos carros. Mobilizada pela escrita deste texto, passo a perceber detalhes que me teriam passado despercebidos. Vejo uma moça que atravessa com seu carro em alta velocidade falando ao telefone celular, eu levo um susto com a batida que ela dá ao atravessar uma lombada; vejo à minha direita o motorista de um carro ameaçando jogar o veículo sobre a moto, que responde chutando o retrovisor. Logo em seguida passa um grande caminhão que carrega carros e onde posso ler, na carroceria, uma frase estampada bem em cima da foto de uma grande mão segurando um carro: "aqui seu carro está em boas mãos”; bem ao lado vejo uma bica de água pequena que escorre do morro por uma brecha na parede onde as famílias que moram na rua, mulheres, crianças, homens e idosos lavam suas roupas e tomam banho. Decido dar meia volta e sair dali imediatamente, porque aquilo tudo começa a me intoxicar. Tento mudar para a calçada, mas isso não ajuda em nada. A gasolina que corre nos motores também corre nas minhas veias. O carroceria de aço dos carros também é a imagem de nossos corpos.

Decido, finalmente, correr dali em direção ao Parque da Água Branca, em busca do oásis. No caminho me pego parada olhando um homem encerando com muito carinho o seu carro branco. Aperto o passo e chego ao parque. Este é um dos parques mais antigos de São Paulo, ele tem uma forte herança do ambiente rural do interior de São Paulo. Pássaros, muitas galinhas, galos e pintinhos, patos e patinhos, peixes, cavalos, gatos por todos os lados (gravei todos estes sons enquanto caminhava, para não esquecer desta beleza fundamental). Caminho entre as árvores, a umidade torna o ar puro, que entra pelo meu nariz e umedece a minha pele. Lembro de Maria e de Marcuse e da Utopia. Se o pensamento utópico tem seu direito em uma teoria crítica, não é por um esforço de elaboração de uma projeto futuro simplesmente, mas pela capacidade de perceber as condições mesmas da liberdade e da felicidade no presente (e também no passado esquecido).

\begin{tabular}{|c|c|c|c|c|}
\hline Q Rovita Dialectus & Ano 8 & n. 14 & Janeiro - Julho 2019 & p. $147-168$ \\
\hline
\end{tabular}




\section{VIDA E MORTE, PROGRESSO E UTOPIA EM HERBERT MARCUSE}

Marília Mello Pisani

Fico com a imagem das pessoas no trânsito da cidade. A sociedade dos carros também é a sociedade das pessoas-carros, daquilo que André Gorz descreveu como o "egoísmo cruel e agressivo dos motoristas de carro que, a cada minuto, assassinam simbolicamente 'os outros', que aparecem a ele como obstáculos materiais à sua própria velocidade” (Gorz: 2005: 74). Lembro então que Marcuse trabalhou especialmente nestas duas dimensões: a profundida em que a racionalidade dominante é introjetada pelos indivíduos e a utopia como elemento fundamental para o pensamento crítico.

\section{Teoria Crítica e Utopia}

A tese de doutorado intitulada Teoria Crítica e Utopia (2017), de Maria Érbia Carnaúba, traz um levantamento cuidadoso dos diferentes momentos de desenvolvimento do conceito de Utopia em Marcuse, que, segundo ela, é um dos conceitos centrais de seu modelo de Teoria Crítica: a tese começa nos anos 30, trata do confronto e do debate com Max Horkheimer; desenvolve a relação com o diagnóstico da Dialética do Esclarecimento, defendendo que o livro O Homem Unidimensional não deve ser lido na chave do pessimismo e do fechamento total de alternativas, uma vez que haveria uma permanente tensão marcada pelo lugar da Utopia; e um terceiro capítulo em que ela trata das afinidades entre Herbert Marcuse e Ernst Bloch, autor de O Princípio Esperança, e desenvolve as implicações para pensar os movimentos sociais contemporâneos a partir de um deslocamento (histórico) do uso do conceito de Utopia. Esta articulação é inédita entre nós. Me interessa acompanhar este terceiro e último movimento de sua tese, onde ela mostra que há uma novidade na abordagem realizada ao longo dos anos 19671979. Importante frisar que a pesquisa de Carnaúba é uma das pioneiras em trabalhar com textos e materiais nunca antes publicados no Brasil. Sob a orientação com John Abromeit durante o estágio de doutorado sanduiche nos Estados Unidos (e de Marcos S. Nobre no Brasil) e próxima ao círculo de pesquisadores vinculados a International Herbert Marcuse Society (Arnold Farr, Andrew Lamas, Charles Reitz, Peter Erwin Jansen, Imaculada Kangussu, Silvio Carneiro, Robespierre de Oliveira, entre outros), ela teve contato com um material inédito e deve se tornar referência nos estudos de Marcuse no Brasil.

O período compreendido entre 1967-1979 é marcado por uma série de textos em que Marcuse articula o trabalho de uma vida com os movimentos sociais emergentes - em torno do tema da revolução e do sujeito revolucionário, do bloqueio da práxis, da relação entre teoria e prática, da utopia e da estética. Esses movimentos surgem fora do âmbito da

\begin{tabular}{|c|c|c|c|c|}
\hline Q Rovita Dialectus & Ano 8 & n. 14 & Janeiro - Julho 2019 & p. $147-168$ \\
\hline
\end{tabular}




\section{VIDA E MORTE, PROGRESSO E UTOPIA EM HERBERT MARCUSE}

Marília Mello Pisani

Nova Esquerda Americana e em tencionamento com este, mobilizando outras estratégias e demandas vindas da juventude estudantil, das mulheres, dos negros e negras americanas/os, latinos e latinas, ecologistas. Esses movimentos não seguem o modelo da luta de classes tradicional ao marxismo e nem o modelo único da uma política representativa, pois nascem com demandas por outras formas de vida, exigindo uma mudança em sua base para além do desenvolvimento repressivo da sociedade do trabalho e das mercadorias - uma outra cultura e uma outra subjetividade. Quais formas de vida são demandadas por essa configuração histórica da Utopia? Que imagem de liberdade elas produzem?

Segundo Carnaúba, é nos fins dos anos 60, sobretudo com a publicação de Ensaio sobre a Libertação [1969] que "torna-se mais claro que Marcuse muda de diagnóstico de época e podemos dizer que a utopia volta a se destacar não apenas como conceito (que aparece muitas vezes), mas também como prática política. Como seria isso?” (Carnaúba: 2017: 259). A pergunta será desenvolvida retomando textos como Tolerância Repressiva, Contrarevolução e Revolta, Paris Lectures at Vincennes University, Marxismo e Feminismo, entre outros. Uma nova configuração conceitual ganha força, com os conceitos de "nova sensibilidade", de Grande Recusa e a dimensão estética.

Tentarei explorar estes conceitos não a partir da explicitação das definições teóricofilosóficas dadas nos textos, que são frágeis caso não mediadas com os movimentos sociais (Carnaúba: 2017: 250, 259). Estes conceitos tornam-se carapaças ocas, invólucros instrumentalizados se não localizados nas bases materiais e históricas com as quais eles se articulam. Eles precisam de corpo e de uma outra racionalidade. Seria nesse sentido que eu entendo que Marcuse cria conceitos eróticos, como tentativa de ligar Eros e Ciência, forma e conteúdo, razão e sensibilidade (como também Adorno desenvolve na Teoria Estética) ${ }^{2}$. Para isso, eu gostaria de relembrar, neste momento, que o nosso ponto de partida é o contexto da sociedade dos carros, das pessoas-carros com seu interior de aço. Como, da crítica da civilização industrial automobilística, é possível pensar a Utopia em Marcuse? As questões anteriores se articulam a essa no desafio de pensar o que poderia e deveria ter sido diferente, para que as mortes de Maria e de Carolina não sejam apenas mais duas na contabilidade geral dos acidentes automotivos.

Para Marcuse, um dos elementos fundamentais dos novos movimentos sociais é o

\footnotetext{
${ }^{2}$ Ver ensaio de Deborah Antunes e Marilia Pisani, "Rumo a um novo manifesto Um diálogo esquecido entre Herbert Marcuse e Theodor Adorno" (2015).

\begin{tabular}{|c|c|c|c|c|}
\hline Revita Alatectus & Ano 8 & n. 14 & Janeiro - Julho 2019 & p. $147-168$ \\
\hline
\end{tabular}
}




\section{VIDA E MORTE, PROGRESSO E UTOPIA EM HERBERT MARCUSE}

Marília Mello Pisani

potencial de recusa da racionalidade repressiva. Penso que podemos encontrar nesse diálogo os elementos necessários para uma Utopia erigida a partir da negação da sociedade dos carros.

Para isso, vou tomar como ponto de partida a crítica da biotecnologia reprodutiva realizada por Gertrude Steuernagel em Marcuse and Biotechnology (1998) e apresentar a reflexão realizada por Marcuse sobre os movimentos ecológicos e feministas, em Ecology and Revolution ([1972]2005) e Marxism and Feminism ([1974]2005). O movimento ecológico e o movimento das mulheres aparecem para Marcuse como a mais radical antítese ao capitalismo avançado e o local de onde pode surgir um novo conceito de revolução, nunca antes imaginado pela teoria marxista, como ele afirma em The Radical Transformation of Norms, Needs and Values (Marcuse: [1977]2017: 51) - porque ele ultrapassa a mudança meramente infraestrutural (socialização) dos meios de produção (tecnologia), para abarcar uma transformação subjetiva mais ampla, nos valores e nas necessidades (uma revolução cultural que poderia dar origem a um novo conceito de socialismo).

O ensaio de Steuernagel nos ajuda a focar uma questão importante da teoria crítica da tecnologia. Ela começa o texto localizando o debate americano recente (década de 90) sobre as leis que envolvem os direitos de propriedade na biotecnologia: reprodução assistida, tratamentos genéticos, clonagem. Um intenso debate público traz à tona, para a cientista política estudiosa dos direitos das Mulheres, que há uma diferença de tratamento nas questões genéticas quando o assunto é reprodução. O interessante do texto, para mim, neste momento, é o deslocamento que a abordagem de Marcuse permite para ela pensar o problema dos direitos genéticos e da propriedade privada: "Marcuse nos ajuda a descartar a ideia de que a tecnologia não é boa nem má em si mesma. Além disso, ele nos força a olhar o sistema atual em que a biotecnologia está inserida e ver como o atual desenvolvimento e implementação da biotecnologia estão sendo usados para servir aos interesses de uma sociedade não livre" (1998: s/).

Surgem então as perguntas incômodas: por que tantos recursos são dispendidos para que mulheres engravidem após a menopausa e para ajudar casais inférteis a conceberem filhos quando a superpopulação é um problema? Por que tantos recursos para ajudar mulheres de cinquenta e sessenta anos a terem filhos? Quem tem acesso às essas tecnologias reprodutivas? "Eu gostaria de sugerir que o desenvolvimento e implementação de tecnologias reprodutivas (...) servem aos interesses de necessidades falsas e distraem as pessoas das perguntas que uma sociedade opressiva não quer que sejam feitas" (1998: s/). Por que tantas mulheres estão adiando a gravidez? Seria porque a sociedade se organiza de tal modo que dificulta que as mulheres

\begin{tabular}{|c|c|c|c|c|}
\hline Qevista Dialectus & Ano 8 & n. 14 & Janeiro - Julho 2019 & p. $147-168$ \\
\hline
\end{tabular}




\title{
VIDA E MORTE, PROGRESSO E UTOPIA EM HERBERT MARCUSE
}

Marília Mello Pisani

tenham filhos na época em que seus corpos estão preparados para isso? Seria porque a sociedade repressiva impõe ao corpo uma produtividade antibiológica, portanto, contraria à vida? Seria porque a sociedade necessita perpetuar a dominação das mulheres através da identificação de seu valor com a reprodução? As tecnologias reprodutíveis não são neutras. Em $O$ Homem Unidimensional: estudos sobre a ideologia da sociedade industrial avançada ([1964] 2015), Marcuse escreve:

\begin{abstract}
Nessa sociedade, o aparato produtivo tende a se tornar totalitário no sentido em que ele determina não apenas as ocupações, habilidades e atitudes socialmente necessárias, mas também as necessidades e aspirações individuais. (...) A maneira pela qual a sociedade organiza a vida de seus membros envolve uma escolha inicial entre alternativas históricas que são determinadas pelo nível herdado de cultura material e intelectual. A própria escolha resulta do jogo de interesses dominantes. Ela antecipa modos específicos de transformar e utilizar o homem e a natureza e rejeita outros. (...) Enquanto universo tecnológico, a sociedade industrial avançada é um universo político, a mais recente etapa na realização de um projeto histórico específico - a saber, a experiência, a transformação e organização da natureza como mero material de dominação (Marcuse: 2015: 36).
\end{abstract}

Deste ponto de vista, não se trata de recusar a tecnologia reprodutiva. Steuernagel sugere que, se as mulheres tivessem a posse de todas as informações e riscos dos tratamentos, seria possível tomar uma decisão consciente pelo tratamento; mas isto é impossibilitado pelas próprias empresas farmacêuticas e seus especialistas. Trata-se, então, de entender o que produz a reprodução assistida como mercado e a quais valores e necessidades corresponde. $\mathrm{Na}$ biotecnologia, a mercantilização da vida ganha um aspecto surpreendente pela apropriação capitalista monopolista da informação genética e das bases mesmas da vida: da saúde, da alimentação, da educação, da locomoção, comunicação etc. "Uma visão libertadora da biotecnologia, baseada numa visão libertadora de ciência, dirigiria nossas energias para triunfar sobre a dor e a doença. Se nós podemos estender a vida, nós precisamos cuidar para que a vida valha a pena ser vivida" (Steuernagel: 1998: s/).

Para Marcuse, as forças sociais capazes de mobilizar uma imagem crítica de uma mudança infraestrutural aliada a uma transformação de valores estariam nos movimentos ecológicos e feministas (ao que ele articula ao movimento negro, a partir de Angela Davis) e ele aposta profundamente nisso em 1974: "eu acredito que o movimento de libertação das mulheres é, talvez, o mais importante e o mais potencialmente radical movimento político que nos temos, mesmo que a consciência desta fato não tenha ainda penetrado na consciência do movimento como um todo" (Marcuse: 2005: 165). Por que e qual imagem de liberdade produzem?

Em Marxismo e Feminismo (2005) Marcuse apresenta seus argumentos para defender a

\begin{tabular}{|l|l|l|l|l|}
\hline Q Povista Dialectus & Ano 8 & n. 14 & Janeiro-Julho 2019 & p. 147-168 \\
\hline
\end{tabular}




\section{VIDA E MORTE, PROGRESSO E UTOPIA EM HERBERT MARCUSE}

Marília Mello Pisani

dimensão revolucionária do feminismo e o que ele chama de "feminismo socialista" (2005: 170). Um primeiro elemento importante que ele destaca é a relação entre o movimento feminista e a Nova esquerda. Para Marcuse, a esquerda continuará fazendo as pazes com a opressão na medida em que não for capaz de absorver a radicalidade da mudança subjetiva que o feminismo revolucionário exige: por isso, podemos dizer, com Marcuse, que a esquerda é feminista ou não é revolucionária.

As mulheres não constituem uma "classe" no sentido originalmente atribuído pelo marxismo, apesar desta categoria atravessar profundamente a luta das mulheres. Mas haveria ainda assim uma autonomia do movimento das mulheres, que exige, da esquerda, incorporar uma mudança cultural e de valores profunda (nas práticas, nos valores e na linguagem) pela transformação social, assim como exige levar a sério a superação da sociedade patriarcal: “O movimento de libertação das mulheres será um processo doloroso, mas eu acredito que ele será necessário, uma etapa vital na transição para uma sociedade melhor para homens e mulheres" (Marcuse: 2005: 172).

A sociedade patriarcal é, para Marcuse, a sociedade da produtividade auto- impulsionada, da agressividade contra a natureza, da competitividade, de racionalidade formal abstrata e instrumental. Ela se confunde, nesse sentido, com a própria forma do Capital: abstração da forma valor em relação às necessidades de uso, a equivalência geral de corpos (mercadorias) diferentes sob o equivalente geral (formal) do dinheiro, a natureza (Terra, Força de trabalho) matematizada e quantificada, etc. Em Eros e Civilização (1999a) Marcuse aproxima este princípio racional patriarcal do mito de Prometeu - arquétipo do princípio de desempenho (rendimento), símbolo do progresso, do labor e da produtividade - ao qual contrapõe Pandora, Orfeu e Narciso, imagens de uma outra relação com a natureza e um outro princípio de realidade não repressivo: outra sexualidade, o canto como forma que apazigua as forças da natureza, a beleza desinteressada. Uma transformação nessas bases (culturais, psicológicas, éticas) exigiria uma reorganização total do aparato produtivo e do trabalho social. Em Natureza e Revolução ([1972] 1973) Marcuse tira incríveis implicações destas ideias - este texto é de grande importância para pensar este debate.

[A produtividade repressiva] tem sido a característica cada vez mais notória da dominação masculina; à medida que o princípio masculino tem sido a forma mental e física dominante, uma sociedade livre seria a negação definitiva deste princípio - seria uma sociedade 'fêmea'. Isto nada tem a ver com o matriarcado; a imagem da mulher como mãe é, em si mesma, repressiva; transforma um fato biológico num valor ético e cultural e, assim, apoia e justifica a repressão social da mulher. Em jogo está, antes, a [ascensão] de Eros sobre a agressão, em homens e mulheres; e isso significa, numa civilização dominada pelo homem, a 'feminilização do macho'. Expressaria a mudança decisiva dos instintos: o enfraquecimento da agressividade primária que, por uma combinação de fatores biológicos e sociais, tem governado a cultura patriarcal (Marcuse: 1973: 77).

\begin{tabular}{|c|c|c|c|c|}
\hline Rovista Dialectus & Ano 8 & n. 14 & Janeiro - Julho 2019 & p. $147-168$ \\
\hline
\end{tabular}




\title{
VIDA E MORTE, PROGRESSO E UTOPIA EM HERBERT MARCUSE
}

Marília Mello Pisani

Essa citação expressa em que medida Marcuse articula feminismo e revolução e onde estaria a potencialidade utópica do movimento. Há no feminismo lutas justas por igualdade econômica, política e social. Marcuse não recusa essas lutas, mas ele pergunta, para a mulheres, se é possível a liberdade dentro de uma sociedade guiada pelo princípio de desempenho e pela dinâmica de exploração do Capital. A radicalidade do feminismo estaria, para ele, na sua capacidade de redefinir os termos da liberdade e a própria noção de socialismo: "igualdade não é ainda liberdade" (2005: 170). Como liberdade, ele entende que a força dessa luta está na demanda por outra forma de vida, em que a vida seja um fim em si mesma, em que a natureza não seja matéria disponível, assim como os corpos e as mentes. Aqui o movimento feminista encontra o movimento ecológico naquilo que Marcuse chama de potencial radical e revolucionário: a saber, a luta pela terra e pela sbrevivência dos povos contra o "terricídio" (Marcuse: 1983: 57) - em inglês ecocide (Marcuse: 2005: 173) -, em nome de uma produtividade não destrutiva, pela autonomia dos seres vivos em relação ao lucro e às necessidades do Capital. Por isso que o movimento ecológico apareceria como uma oposição radical ao capitalismo, porque questiona a própria modalidade de produção e o estilo de consumo.

\begin{abstract}
A luta pela ampliação do mundo de beleza, de não-violência e de serenidade é uma luta política. A insistência nestes valores, em restaurar a Terra como meio ambiente humano, é não só uma ideia romântica, estética e poética, que concerne somente aos privilegiados; é hoje uma questão de sobrevivência. (...) A meta continua sendo o bem-estar, mas [conseguido] pela conquista de uma vida livre do terror, da escravidão em relação ao salário, da violência, do fedor, do barulho infernal de nosso mundo industrial capitalista. Não é o caso de embelezar o abominável, de ocultar a miséria, de desodorizar o mau cheiro, de plantar flores no cárcere, nos bancos, nas fábricas: não se trata de purificar a sociedade atual, e sim substituí-la (Marcuse: 2005: 175).
\end{abstract}

O caráter espontâneo dos movimentos sociais contemporâneos e a sua capacidade de autogestão [self-determination, autogestion] são modelos de outras formas de luta que deveriam ser, segundo ele, modelos para uma revisão da Esquerda (Marcuse: 2005: 173). Nessa revisão das lutas políticas, a Utopia aparece com uma forma de pensamento que nos ajuda a vislumbrar, ou melhor, relembrar, imagens de felicidade que poderiam guiar uma nova forma de fazer político.

Importante notar que as ideias de Marcuse não foram recebidas sem críticas pelas mulheres. Sobretudo o modo como ele lida com a ideia de natureza será alvo de recorrentes debates - afinal, mesmo entendendo o "feminino" como uma segunda natureza, ele funda e

\begin{tabular}{|c|c|c|c|c|}
\hline Q Rovita Dialectus & Ano 8 & n. 14 & Janeiro - Julho 2019 & p. $147-168$ \\
\hline
\end{tabular}




\section{VIDA E MORTE, PROGRESSO E UTOPIA EM HERBERT MARCUSE}

Marília Mello Pisani

mantém uma ideia de natureza (seja biológica ou cultural) que será um dos pontos centrais da crítica de Donna Haraway no Manifesto ciborgue ([1989] 2009); de Gertrude Steuernagel em Marcuse, the Women's Mouvement, and Women's Studies (1994) e se torna a polêmica no debate entre Marcuse, Silvia Bovenschen e Marianne Schuller na entrevista Imágenes de la Feminilidad ([1978]1980). Penso que as críticas são pertinentes, porque atualizam as questões que o feminismo vai desenvolver após Marcuse; e porque mostram que, apesar de as qualidades femininas serem uma segunda natureza que, como "negação determinada", poderiam confrontar com o princípio de desempenho entendido como sociedade patriarcal, ainda assim penso que deve-se levar a sério aquilo que as mulheres dizem sobre si mesmas. Não é o caso de avançarmos nestas críticas, eu queria apenas pontuar e lembrar que há muito a ser desenvolvido.

\section{Vida e Utopia}

Em 2014, recebi um convite para compor a banca de qualificação do Doutorado de Maria Érbia. Recebi o trabalho, fiz minhas leituras e comentários, porém, na semana mesma da qualificação, eu tive um problema cirúrgico, fui internada por cinco dias e não pude comparecer. Nunca pudemos retomar essa conversa, apesar de termos tentado agendar diversas vezes. Lembro que eu tinha um ponto preciso que queria conversar com ela, mobilizada pelo entusiasmo das possibilidades de articular utopia, movimento social e feminismo. Lendo hoje a tese acabada, vejo que, independente dessa conversa, ela chegou no mesmo lugar que eu me entusiasmara naquele momento. Trata-se do lugar do feminismo socialista e negro [Black feminism] em Angela Davis para pensar/agir e avançar na contribuição de Marcuse para os movimentos sociais, levando em conta a importância da desnaturalização das formas de repressão (mais-repressão) raciais, de gênero e de classe para uma revisão do conceito de Utopia, tão central para a sua Teoria Crítica.

A Tese de Maria E. Carnaúba (2017) apresenta especialmente os debates de Marcuse com o feminismo socialista que ela mobiliza a partir de Angela Davis. Penso que a imagem de liberdade que ela apresenta a partir do movimento feminista pode encontrar desdobramentos no movimento feminista abolicionista e também na ecologia. Fica assim a impressão de que a Teoria crítica de Marcuse pode apontar para um terreno comum da política contemporânea, numa teoria dos movimentos sociais e da revolução.

Assim, no próprio movimento está contida a imagem não só de novas instituições sociais, mas

\begin{tabular}{|c|c|c|c|c|}
\hline Rovita Dialectus & Ano 8 & n. 14 & Janeiro - Julho 2019 & p. $147-168$ \\
\hline
\end{tabular}




\section{VIDA E MORTE, PROGRESSO E UTOPIA EM HERBERT MARCUSE}

Marília Mello Pisani

também de uma mudança de consciência, de uma mudança nas necessidades instintivas de homens e mulheres, livre das exigências da dominação e da exploração. E este é o potencial mais radical e subversivo do movimento. (...) O que está em jogo nesta transcendência é a negação dos valores exploradores e repressivos da civilização patriarcal. O que está em jogo é a negação dos valores impostos e reproduzidos na sociedade pela dominação masculina. E tal subversão radical de valores nunca pode ser o mero subproduto de novas instituições sociais. Deve ter suas raízes nos homens e mulheres que constroem as novas instituições (Carnaúba: 2017: 288).

Esta seria imagem de liberdade contida no feminismo que só pode se dar como prática de liberdade. É uma imagem formulada como narração de uma liberdade objetiva. Por isso a necessidade de uma outra forma, de uma outra linguagem.

Por que a questão racial é tão importante para a Grande recusa? Por que o movimento feminista e abolicionista é a expressão da Teoria crítica? Para Angela Davis, a "teoria crítica radical" (Davis: 2017: viii) de Marcuse está relacionada com a sua práxis como intelectual engajado; por sua vez, Marcuse escreve para Davis, em carta de 18 de novembro de 1970, que a prática engajada de Angela é a melhor expressão do que é o pensamento crítico e de como os conceitos filosóficos de liberdade e de justiça se realizam.

O mundo no qual você cresceu, seu mundo (que não é o meu) foi [repleto de] crueldade, miséria e perseguição. Reconhecer estes fatos não solicitou muita inteligência e sofisticação, mas imaginar que eles poderiam e devem ser transformados requer pensamento, pensamento crítico: saber como estas condições são superadas, quais forças as sustentam, e [quais] as possibilidades de liberdade e justiça. Isto, acredito, vocêê aprendeu em seus anos de estudo. E você aprendeu algo mais, a saber: que quase todas as figuras celebradas da civilização ocidental - a mesma civilização que escravizou seu povo - estava preocupada com uma coisa: a liberdade humana. (...) Então, você sentiu que a ideia filosófica, a menos que ela fosse uma mentira, deveria se transformar em realidade: que ela continha um imperativo moral a ser levado para a sala de aula, para o campus, e que vai adiante e ajuda os outros, sua própria gente a quem você̂ ainda pertence - a despeito (ou mesmo por causa) de seu sucesso no Establishment branco. Mas você lutou por nós também, a quem precisamos de liberdade e a quem quer a liberdade para todos aqueles que ainda não são livres. Nesse sentido, sua causa é nossa causa (Marcuse: 2005: 50).

Para Angela Davis, há uma forte relação entre a Grande Recusa e os movimentos abolicionistas (Davis: 2017). A Black radical tradition de luta pela liberdade seria a manifestação histórica da Grande Recusa. Pois esta não seria uma luta apenas dos negros, mas de todos/todas aqueles/aquelas que recusam as estruturas de opressão e lutam pela liberdade: se o capitalismo é também "capitalismo racial”, e também capitalismo generificado, então isto precisa ser levado a sério nas lutas políticas e pela Esquerda. Por isso, o feminismo negro [Black feminism] aparece para Davis como um dos mais importante movimentos, pela sua capacidade de localizar a ideia de liberdade como compreensão e recusa da experiência profunda de

\begin{tabular}{|c|c|c|c|c|}
\hline Q Rovista Dialectus & Ano 8 & n. 14 & Janeiro - Julho 2019 & p. $147-168$ \\
\hline
\end{tabular}




\section{VIDA E MORTE, PROGRESSO E UTOPIA EM HERBERT MARCUSE}

Marília Mello Pisani

produção do corpo e da vida sob a violência e a injustiça da escravidão e do preconceito racial. Isso quer dizer que o povo negro que lutou pela sua liberdade deve ser a medida da cidadania e da pessoa: "Mas se podemos enriquecer ainda mais nossos sonhos, o que aconteceria se nós imaginássemos que a mulher negra como a medida da humanidade?” (Davis: 2017: x).

Há uma ligação profunda e passível de ser mapeada historicamente entre a escravidão do povo negro africano (conforme Mulheres, Raça e Classe (2016) de Angela Davis), a queima das mulheres na Idade média (conforme Calibã e a Bruxa: mulheres, corpo e acumulação primitiva (2017) de Silvia Federici) e o genocídio indígena (conforme A Queda do Céu: palavras de um xamã Yanomani (2015) de Davi Kopenawa e Bruce Albert) como formas fundamentais de exploração do trabalho e da riqueza que estão na base da acumulação capitalista e das formas atuais de vida, já naturalizadas. O discurso que oculta a profundidade da gênese histórica da violência se torna ideológico no sentido de encobrimento da verdade. De onde surge da necessidade de desnaturalização dessas formas de opressão como Grande recusa. Segundo Silvio Carneiro, a "Grande Recusa é a verdade da falsidade do todo social” (2015: 332):

A black music traz consigo novos elementos para se pensar o contentamento: o contraste com o sofrimento que não deveria estar lá... Marcuse encontra na arte negra um material estético que organiza na resistência swingada que traz consigo o sofrimento dos corpos, uma nova racionalidade. (...) Marcuse reconhece na arte do movimento negro não apenas uma arte política, mas a arquitetura de uma sociedade livre que se prepara na constituição de sua forma estética (Carneiro: 2015: 338).

No livro Hegel e o Haiti (2017), Susan Buck-Morss nos apresenta movimentos fundamentais para uma renovação da Teoria crítica e do pensamento crítico em uma perspectiva antiracista. Este livro me parece uma autoreflexão da Teoria crítica sobre si mesma na perspectiva de uma Grande Recusa. Logo nas primeiras páginas ela denuncia a especialização e o isolamento acadêmico do conhecimento e justifica a sua abordagem do filósofo Hegel, especialmente a passagem da dialética do senhor/escravo na Fenomenologia do Espírito, a partir da Revolução do Haiti - que foi, segundo Angela Davis, a primeira democracia racial do Ocidente (Davis: 2017: ix). Sobre isso, Susan Buck-Morss escreve: “caso certas constelações de fatos consigam penetrar fundo o bastante na consciência intelectual, ameaçarão não apenas as narrativas veneráveis, mas também as entrincheiradas disciplinas acadêmicas que as reproduzem" (2017: 34). Ao longo do livro ela mostra, a partir da materiais históricos, que Hegel estava acompanhando muito de perto, através de jornais e relatos, a Revolução haitiana sem, no

\begin{tabular}{|c|c|c|c|c|}
\hline Rovita Dialectus & Ano 8 & n. 14 & Janeiro - Julho 2019 & p. $147-168$ \\
\hline
\end{tabular}




\section{VIDA E MORTE, PROGRESSO E UTOPIA EM HERBERT MARCUSE}

Marília Mello Pisani

entanto, mencionar uma só passagem sobre o acontecimento histórico. Essa relação entre o acontecimento e o conceito entra definitivamente na ideia de liberdade de Hegel e na dialética do reconhecimento. Porém, na medida em que invisibiliza a história e suas vozes (2017: 79), e na medida em que seu pensamento vai ficando mais sistemático e mais acadêmico, ele se mete em uma contradição exemplar que o conduz ao racismo de seus últimos trabalhos. A cena que fecha o livro de Buck-Morss pode nos ajudar a situar esta contradição.

A Revolução Francesa havia acabado de acontecer. A luta pela liberdade, igualdade e fraternidade tinha ganhado força histórica. Ao mesmo tempo, estes ideais permearam as colônias europeias. O povo do Haiti foi o primeiro a levar a sério as implicações universais destas demandas na luta contra a escravidão pela liberdade. Porém, os franceses dependiam economicamente da colônia, ou seja, estes ideais não podiam universalizar-se sem quebrar o monopólio da apropriação de matéria prima e do trabalho através da violência pelas metrópoles europeias. Soldados franceses são enviados ao Haiti para reprimir a revolta, mas, quando chegam, os ex-excravos cantam o hino nacional francês. $\mathrm{O}$ racismo europeu, ancorado na luta de classes, escolheu por não levar adiante a universalização do conceito de liberdade; com isso criou-se uma cisão profunda entre a consciência da opressão no discurso e as ações que poderiam colocar em questão os privilégios. Este mecanismo psicológico, que tem gênese material, é o cerne de vários debates importantes, como Franz Fanon (o modo como ele vai ler a dialética do senhor/escravo), Lélia Gonzalez (conceito de denegação no racismo brasileiro), Neusa Santos Souza (quando, mobilizada pela necessidade de um discurso sobre si mesma, volta-se para a experiência da pessoa negra no Brasil). Trabalhos que precisam ser trazidos e desenvolvidos em uma Teoria crítica feita a partir do Brasil.

(...) os soldados franceses que, enviados à colônia por Napoleão, ao ouvirem esses ex-escravos contando a Marselhesa, perguntaram-se em voz alta se não estariam lutando do lado errado; o regimento polonês... desobedeceu a suas ordens e recusou a afogar os seiscentos dominguenses capturados (...). E se, a cada vez que a consciência dos indivíduos ultrapassasse os limites das constelações atuais de poder e percebesse o significado concreto da liberdade, este fosse avaliado como um momento, ainda que transitório, da realização do espirito absoluto? Quais outros silêncios teriam que ser quebrados? Quais histórias in-disciplinadas teriam ainda que ser contadas? (Buck-Morss: 2017: 118).

A Grande Recusa de Marcuse impulsiona o pensamento filosófico a um deslocamento profundo a partir da nossa história. São necessárias ações que modifiquem os lugares institucionais e subjetivos que continuam a propagar os silenciamentos. Ações que desnaturalizem as violências e que reabilitem historicamente os ideais objetivos de liberdade e

\begin{tabular}{|l|l|l|l|l|}
\hline Gevista Dialectus & Ano 8 & n. 14 & Janeiro-Julho 2019 & p. $147-168$ \\
\hline
\end{tabular}




\section{VIDA E MORTE, PROGRESSO E UTOPIA EM HERBERT MARCUSE}

Marília Mello Pisani

felicidade. As hierarquias raciais devem ser abolidas, tanto quanto as de gênero e as de classe. Através dessas três categorias de análise, com Marcuse, podemos fazer a mediação dialética necessária, entre parte e todo, num mundo histórico, portanto, engendrado. As coisas poderiam ser diferentes. Por que elas são assim? Quais práticas e acordos, quais ideias e valores produziram esta realidade que favorece a agressividade e a dialética bloqueada de progresso e destruição? Quais fazem a sua manutenção? Onde estariam as/os agentes políticos de uma transformação radical nessas bases?

Marcuse remonta à gênese do passado mitológico, à antropologia, às artes, aos movimentos sociais e culturais vistos por ele como emergência de uma nova sensibilidade revolucionária. Nisso encontra o terreno comum da libertação da natureza e do corpo como ideal ético e político, como vemos em Natureza e Revolução (1973). E quando ele faz isso, ele liga as lutas por outas formas de vida, seja a luta pela terra do Movimentos Sem Terra (MST-Brasil), sejam as lutas indígenas no Brasil, que se erguem há séculos numa defesa radical da natureza e que me parece ser, hoje, a imagem mais potente de uma Grande Recusa.

Ações estão sendo feitas nesse sentido, mesmo com toda a pressão dos grupos políticos e dos meios de comunicação de massa para esconder e demonizar as formas de resistência. $\mathrm{O}$ trabalho de muitos e muitas segue nesse sentido e eu gostaria de citar a pesquisadora Lea Tosold (com quem venho aprendendo tanto sobre todas estas questões). No final de sua tese de doutorado (2018) sobre desnaturalização da violência e autodeterminação dos povos indígenas (um trabalho inspirador para as pesquisas de Marcuse no Brasil), ela discute teoria política à luz da luta e da resistência do povo Munduruku. Ao final do trabalho ela anexa uma série de cartas escritas por esses povos aos governantes e ao povo brasileiro tentando apresentar e justificar a sua luta contra a construção de hidroelétrica Belo Monte no Rio Tapajós - um projeto que uniu esquerda e direita, mercado, agronegócio, mineiros, capital produtivo e financeiro em torno de um modelo de desenvolvimento e de progresso unidimensional. Tidos como contrários ao desenvolvimento, esses povos perguntam:

Nós somos a gente que vive nos rios em que vocês querem construir barragens. Nós somos Munduruku, Juruna, Kayapó, Xipaya, Kuruaya, Asurini, Parakanã, Arara, pescadores e ribeirinhos. Nós somos da Amazônia e queremos ela de pé. Nós somos brasileiros. O rio é nosso supermercado. Nossos antepassados são mais antigos que Jesus Cristo. Vocês estão apontando armas contra a nossa cabeça. Vocês sitiam nossos territórios com soldados e caminhões de guerra. Vocês fazem o peixe desaparecer. Vocês roubam os ossos dos antigos que estão enterrados em nossas terras. Vocês fazem isso porque têm medo de nos ouvir. De ouvir que não queremos barragem. De entender porque não queremos barragem. (Carta do povo munduruku referente à ocupação de Belo Monte, Vitória do Xingu (PA), de 2 de maio de 2013. Apud Tosold: 2018: 279).

\begin{tabular}{|l|l|l|l|l|}
\hline Revista Q Dialectus & Ano 8 & n. 14 & Janeiro-Julho 2019 & p. $147-168$ \\
\hline
\end{tabular}




\section{VIDA E MORTE, PROGRESSO E UTOPIA EM HERBERT MARCUSE}

Marília Mello Pisani

A energia virá apenas para favorecer as grandes empresas, como as mineradoras e as multinacionais. A hidrelétrica não gerará energia para as pequenas populações que não têm condições de pagar energia cara. Então, com a barragem construída, virão mais outros grandes projetos de destruição: a ferrovia, a hidrovia do rio Tapajós para escoar grãos de soja, para exportar para o exterior. (...) O governo, com seu projeto, não traz "progresso e nem desenvolvimento", só traz a morte. (Carta aberta do povo munduruku do Alto e Médio Tapajós em apoio à luta de (r)existência guarani- kaiowá e ka'papor, de 15 de julho de 2015 apud Tosold: 2018: 308-309).

Os povos indígenas sabem de onde vem a Grande Recusa e o que é que mobiliza a urgência e a força do pensamento utópico. Esse pensamento não existe em alguma esfera transcendental, eles são atuais, eles existem aqui e agora nas histórias de resistências. E são esses valores e práticas que indicam o caminho para uma cosmologia da não violência e da beleza que não dissocia presente, passado, futuro (e que coloca em risco as vidas do presente em nome de uma ideia de futuro que não contempla a sobrevivência). A sociedade industrial avançada, com sua poluição e desperdício programado, com seu ideal de progresso necropolítico, coloca a vida à serviço de morte. Por isso, eu não aceito a morte de Maria Érbia Carnaúba, eu não aceito a morte das crianças nas favelas do Rio, a morte das mulheres e do povo negro, nem a morte de Marielle Franco, ou de qualquer pessoa ou ser da natureza que tenha tido a vida tornada indigna. Há mediações importantes que ligam estas mortes e o desafio está em conseguir elaborá-las. Maria Érbia sabia, com toda sua luta, que Marcuse é um auxiliar potente para esses enfrentamentos. Vive Maria Érbia Carnaúba, não apenas entre os Manacás do jardim, mas em nós e entre nós.

\section{Referências:}

Alves, Luiz Roberto. Grande ABC: culturas que excedem o lugar culturalizado. Santo André: Alpharrabio edições, 2009.

Benjamin, Walter. "Experiência e pobreza". In.: Magia e Técnica, Arte e Política (Obras escolhidas). São Paulo: Editora Brasiliense, 1994.

Buck-Morss, Susan. Hegel e o Haiti. São Paulo: edições n -1, 2017.

Carnaúba, Maria Érbia. Marcuse e a psicanálise: teoria crítica sob a análise da teoria da repressão. Dissertação de Mestrado. Campinas: UNICAMP, 2012.

Teoria Crítica e Utopia. Tese de Doutorado. Campinas: UNICAMP, 2017.

Carneiro, Silvio. R. Poder sobre a vida: Herbert Marcuse e a biopolítica. Tese de Doutorado. São Paulo: USP, 2014.

Davis, Angela. "Foreword: Abolition and Refusal". In.: Herbert Marcuse and Contemporary

\begin{tabular}{|l|l|l|l|l|}
\hline Q Povista Dialectus & Ano 8 & n. 14 & Janeiro-Julho 2019 & p. 147-168 \\
\hline
\end{tabular}




\section{VIDA E MORTE, PROGRESSO E UTOPIA EM HERBERT MARCUSE}

Marília Mello Pisani

Social Movements. Editado por Lamas, Andrew; Todd, Wolfson; Funke, Peter N. Filadelfia, Londres, Toquio: Temple University Pressa, 2017.

. "Marcuse's Legacies". In.: Herbert Marcuse: a critical reader. Editado por Abromeit, John; Cobb, Mark. New York: Routledge, 2004.

Mulheres, raça e classe. São Paulo: Boitempo editorial, 2016. Dumont, René. A utopia ou a morte. Rio de Janeiro:Paz e Terra, 1975.

Federici, Silvia. Calibã e a bruxa: mulheres, corpo e acumulação primitiva. Tradução Coletivo Sycorax. São Paulo: Elefante, 2017.

Gonzalez, Lélia. "Racismo e sexismo na cultura brasileira". In.: Revista Ciências Sociais Hoje, Anpocs, p. 223-244, 1984.

Gorz, André. “A ideologia social do automóvel”. In Ludd, Ned (org.). Apocalipse motorizado: a tirania do automóvel em um planeta poluído. São Paulo: Conrad Editora do Brasil, 2005.

Haraway, Donna. "Manifesto ciborgue: ciência, tecnologia, e feminismo-socialista no final do século XX". In.: Antropologia do ciborgue: as vertigens do pós-humano. Belo Horizonte: Editora Autêntica, 2009.

Kopenawa, Davi; Albert, Bruce. A queda do céu: palavras de um xamã yanomami. São Paulo: Companhia das letras, 2015.

Marcuse, Herbert. Transvaluation of values and radical social change: five lectures, 1966- 1976. Editado por: Jansen, Peter E.; Surak, Sarah; Reitz, Charles. Toronto: International Herbert Marcuse Society, York University, outubro de 2017.

O homem unidimensional: estudos sobre a ideologia da sociedade industrial avançada. São Paulo: Edipro, 2015.

. The New Left and the 1960s. Editado por Kellner, Douglas. New York: Routledge, 2005 .

. Eros e civilização: uma interpretação filosófica de Freud. Rio de Janeiro: Zahar, 1999a.

. "Algumas implicações sociais da tecnologia moderna". In.: Tecnologia Guerra e Fascismo. Editado por Douglas Kellner. Snao Paulo: edotira UNESP, 1999 b.

"Ecologia e crítica da sociedade moderna". In.: Herbert Marcuse: a grande recusa hoje. Petrópolis: Editora Vozes, 1999c.

“A ecologia é revolucionária”. In.: Oitenta, número 8, p. 55-58, 1983.

Contra Revolução e Revolta. Rio de Janeiro: Zahar, 1973.

\begin{tabular}{|c|c|c|c|c|}
\hline Rovita Dialectus & Ano 8 & n. 14 & Janeiro - Julho 2019 & p. $147-168$ \\
\hline
\end{tabular}


. Counter-Revolution and Revolt. Boston: Bacon Press, 1972.

. On Essays of Liberation. Beacon Press, 1969.

1966.

. Eros and Civilization: a philosophical inquiry into Freud. Boston: Bacon Press,

Marcuse, Herbert; Habermas, Jurgen; Bovenschen, Silvia; Schuller, Marianne, y otros. Conversaciones con Herbert Marcuse. Barcelona: Gedisa, 1980.

Pisani, Marilia. "Marcuse está superado? A grande recusa a Marcuse ou porque ainda é preciso falar em revolução". In Zuin, Antonio A. S.; Franco, Renato; Lastória, Luiz A. C.. Teoria Crítica no Brasil e na América Latina. São Paulo: Nankin, 2016.

; Antunes, Deborah. "Rumo a um novo manifesto: um diálogo esquecido entre Herbert Marcuse e Theodor Adorno". In.: Revista ArteFilosofia, n. 18. Ouro Preto: UFOP, 2016.

Santos, Neusa Souza. Tornar-se negro: ou, as vicissitudes da identidade do negro brasileiro e a ascensão social. Rio de Janeiro; Graal, 1983.

Steuernagel, Gertrude. "Marcuse, the Women's Movement, and Women's Studies”. In.: From de New Left to the Next Left. Editado por Bokina, John; Lukes, Thimoty. University Press of Kansas, 1998. . "Marcuse and biotechnology". In.: Negations, winter 1998, pp. 44-55.

Tosold, Lea. Autodeterminação em três movimentos: a politização de diferenças sob a perspectiva da desnaturalização da violência. Tese de Doutorado. São Paulo: USP, 2018. 